REVIEW

\title{
Proarrhythmic effects of adenosine: a review of the literature
}

\author{
M L Mallet
}

Emerg Med J 2004;21:408-410. doi: 10.1136/emj.2004.016048

Adenosine is widely used as an antiarrhythmic agent for the investigation and management of both narrow complex and, less often, broad complex tachycardias. Over the past 10 years or so, reports of severe bradycardias and tachyarrhythmias being induced by this agent have appeared in the literature. As adenosine is increasingly used in emergency departments and indeed outside the hospital setting, a greater awareness of these potential problems is important. In this paper the evidence for such effects is summarised, and the mechanisms involved discussed.

Correspondence to: Dr M L Mallet, Medical Assessment Unit, Royal United Hospital, Combe Park, Bath BA1 3NG, UK; mark.mallet@ruh-bath. swest.nhs.uk

Accepted for publication 1 June 2003
A denosine is considered first line therapy for the investigation and termination of supraventricular tachycardias because of its efficacy and safety. It is also being used in some areas to aid in the diagnosis of broad complex tachycardias, usually if they have not responded to lignocaine (lidocaine). A number of studies and reports, however, indicate that the drug can cause severe bradyarrhythmias and also both ventricular and supraventricular tachycardias, some of which have been life threatening. These problems with adenosine are uncommon, but they may not yet be widely known in emergency departments. This paper seeks to raise the awareness of these problems and describes the underlying mechanisms.

\section{REPORTS OF BRADYARRHYTHMIAS}

The side effects of bronchospasm and chest pain after the administration of adenosine are commonly encountered but, even if rated severe, are always transient. ${ }^{1}$ Pauses and minor bradyarrhythmias are also well known as they are frequently encountered, but occasionally these can be significant: transient sinus arrest, bifascicular block, ${ }^{2}$ and complete heart block $^{3}$ have occurred, the latter in a patient who had also been treated with digoxin and verapamil. Ventricular standstill and asystole ${ }^{3}$ have also been reported, and in one prospective series asystole $>4$ seconds occurred in $7 \%$ of patients given adenosine. ${ }^{5}$ In one patient treated with adenosine out of hospital asystole was fatal. ${ }^{6}$ Prolonged sinus arrest and bradycardia after the administration of adenosine have resulted in syncope $^{7}$ and seizures, ${ }^{8}$ in one case in a patient undergoing myocardial perfusion imaging. ${ }^{9}$ Fetal bradycardia has also been reported after treatment of a maternal supraventricular tachycardia with adenosine. ${ }^{10} \mathrm{~A}$ further 30 unpublished cases of sinus arrest or asystole had been reported to the manufacturers by mid-199911; anecdotal experience suggests that significant bradyarrhythmias may be more common than has been reported.

\section{REPORTS OF TACHYARRHYTHMIAS}

Ventricular ectopy and non-sustained monomorphic ventricular tachycardia (VT) are frequently seen after the administration of adenosine, $^{12}$ and non-sustained VT has also occurred during pharmacological stress testing with adenosine. ${ }^{13}$ Episodes of non-sustained polymorphic VT have been reported, both in patients with structurally normal hearts and normal QT intervals, ${ }^{14-16}$ and in the presence of congenital $^{17}$ and acquired ${ }^{18}$ prolonged QT interval. These are of little importance and require no intervention. Significant tachyarrhythmias are more rarely encountered, but can be of many different types: these will be considered in more detail.

After the administration of adenosine, sustained torsades de pointes requiring cardioversion $^{19}$ or procainamide ${ }^{20}$ has occurred; one such case in a patient with a drug induced prolonged QT interval. Patients predisposed to ventricular tachyarrhythmias may have these events triggered by adenosine induced pauses or ventricular ectopy; however some of the reported cases were not pause dependent, and the mechanism for these instances of torsades is less clear. Two cases of ventricular flutter degenerating into fibrillation have been reported, ${ }^{21} 22$ one in an elderly woman who had previously been given digoxin and verapamil. Ventricular fibrillation has been seen after adenosine in a patient with stable $\mathrm{VT}^{23}$ and also in three patients with preexcited atrial fibrillation. ${ }^{24-26}$ The details of a further eight cases of ventricular fibrillation remain unpublished. ${ }^{11}$ Hernandez and Ribeiro have discussed ${ }^{27}$ the mechanisms involved in the excitatory effects of adenosine on ventricular automaticity.

Dangerous increases of the ventricular rate in atrial flutter have followed the administration of adenosine, with conduction increasing from 2:1 to $1: 1$ after a brief period of high grade atrioventricular block. ${ }^{328-30}$ Three of these five reported cases required electrical cardioversion. The secondary enhancement of atrioventricular (AV) nodal conduction following initial AV block was thought to be related to sympathetic activation, which was then perpetuated by the onset of 1:1 conduction. Ventricular flutter has also occurred after adenosine in the context of ethanol intoxication. ${ }^{31}$ A similar transient rapid increase in the ventricular rate in the context of

Abbreviations: VT, ventricular tachycardia; AV, atrioventricular 
normally conducted atrial fibrillation has been reported. ${ }^{32}$ This effect was similarly attributed by the author to an increase in sympathetic discharge predominating over the atrioventricular nodal blocking action of adenosine.

Garratt et al found supraventricular proarrhythmic effects in three patient ${ }^{33}$ : a rapid pre-excited atrial fibrillation which was poorly tolerated and subsequently terminated by intravenous flecainide, a pronounced acceleration of an AV re-entrant tachycardia, and a rapid pre-excited atrial tachycardia that required atrial pacing for termination. None of these arrhythmias had occurred previously, and all resulted in severe haemodynamic compromise. Atrial arrhythmias therefore can themselves be induced by adenosine, including atrial tachycardias and atrial flutter. ${ }^{34}$ In fact, the induction of atrial fibrillation by adenosine is now well recognised, ${ }^{35-38}$ and in some more cases has been associated with ventricular preexcitation and haemodynamic collapse. ${ }^{25} 3940$

Adenosine is effective in terminating AV nodal re-entry tachycardias, but these have also been reported as having been induced by adenosine ${ }^{41}$; indeed Curtis et al found that low dose adenosine could induce AV nodal re-entrant tachycardias in 9 of 16 patients who were known to experience this tachycardia. The effect of adenosine on the underlying dual AV node pathways in these patients was investigated, and in common with other workers, ${ }^{42}$ adenosine was shown preferentially to block the fast antegrade pathway, thus allowing a re-entry circuit to develop. A similar response to adenosine has been observed when it was erroneously given to a patient with a sinus tachycardia (personal communication), who had presented to the emergency department with a history of recurrent palpitation; on three consecutive occasions a brief period of narrow complex tachycardia (probably AV nodal re-entry tachycardia) was induced, followed by return to sinus tachycardia.

Adenosine has also been shown to provoke an AV re-entry tachycardia ${ }^{43}{ }^{44}$; in these patients a critical prolongation of antegrade AV nodal conduction was thought to have allowed retrograde activation of the atrium via an accessory pathway and thus the emergence of the reciprocating tachycardia. As already mentioned, adenosine has also been found to increase the ventricular rate substantially in an existing AV re-entry tachycardia ${ }^{33}$; in this case it was thought to be caused by an increase in the rate of retrograde conduction through the AV node. Two further cases have been reported in which adenosine caused a similar immediate increase in the rate of a narrow complex tachycardia (see table 1 ). ${ }^{45}$

\section{DISCUSSION}

Adenosine shortens atrial action potentials, reducing the effective refractory period and thus promoting the development of atrial flutter and fibrillation. In addition, adenosine causes a reflex increase in circulating catecholamine levels

\section{Key points}

- Adenosine is generally a safe and effective antiarrhythmic agent

- It can cause clinically significant bradyarrhythmias and tachyarrhythmias, which may rarely be life threatening

- Clinically significant interactions can occur, especially with dipyridamole and theophyllines

- Extra caution is required with the elderly population and in patients with sinus node disease

- Adenosine should only be given where the expertise and facilities for managing its side effects are available
Table 1 Reported arrhythmias precipitated by adenosine

\begin{tabular}{ll}
\hline Bradyarrhythmias & $\begin{array}{l}\text { Prolonged sinus bradycardia, sinus arrest } \\
\text { bifascicular block, complete heart block } \\
\text { ventricular standstill, asystole }\end{array}$ \\
& Non-sustained ventricular tachycardia \\
Ventricular & sustained torsades de pointes \\
tachyarrhythmias & Ventricular flutter, ventricular fibrillation \\
Supraventricular & Atrial flutter, atrial tachycardia, atrial \\
tachyarrhythmias & fibrillation \\
& Rapidly conducted atrial flutter and atrial \\
& fibrillation \\
& Pre-excited atrial fibrillation and atrial \\
& tachycardia \\
& AV and AV nodal re-entry tachycardias \\
& increased rate of AV re-entry tachycardia
\end{tabular}

and sympathetic nerve traffic by sympathetic stimulation in the carotid body chemoreceptors. ${ }^{46}$ This results in a transient sinus tachycardia and atrial or ventricular ectopy, and these ectopics may provoke the reinitiation of re-entrant arrhythmias. ${ }^{177}$ As discussed above the catecholamine release is also thought in some patients to underlie the increased conduction velocity in accessory AV pathways that can be manifest as a problematic tachycardia. ${ }^{48}$

The negative chronotropic action of adenosine can be particularly pronounced in the presence of sinus node dysfunction, and this has in fact been proposed as the basis for a non-invasive diagnostic test for sick sinus syndrome. ${ }^{49}$ Particular care therefore needs to be taken in such patients, who may present with a tachycardia as part of a tachy-brady syndrome: these patients are especially prone to developing prolonged pauses or asystole. ${ }^{9}$ Animal studies ${ }^{50}$ suggest that increasing age may predispose to increased functional $A_{1}$ receptor sensitivity and impaired adenosine transport, and would imply that extra caution be exercised in older patients. Lower doses should be used if the drug is administered centrally. ${ }^{51}$

There are a few significant drug interactions with adenosine that must be borne in mind. Patients taking dipyridamole (including combination preparations with aspirin) need a lower dose of adenosine as dipyridamole blocks its cellular uptake and thus inhibits its metabolism. ${ }^{52}$ Care must also be exercised with patients taking carbamazepine, which increases the action of adenosine, and can cause additional AV block. Conversely, methylxanthine compounds such as theophylline and caffeine inhibit adenosine competitively at the $\mathrm{A}_{1}$ receptor, and therefore can reduce or block its action, although there is some suggestion that long term administration of these agents may lead to up-regulation of the $A_{1}$ receptors. ${ }^{53}$ These patients therefore usually but not always require higher doses of adenosine (see table 2 ).

Table 2 Patient groups requiring particular care

\begin{tabular}{ll}
\hline $\begin{array}{l}\text { Potential for enhanced effects of Elderly people } \\
\text { adenosine }\end{array}$ & $\begin{array}{l}\text { Sinus node dysfunction } \\
\text { Dipyridamole } \\
\text { Carbamazepine } \\
\text { Drugs affecting AV conduction } \\
\text { (digoxin, verapamil, } \beta \text { blockers) }\end{array}$ \\
$\begin{array}{l}\text { Potential for reduced effect of } \\
\text { adenosine }\end{array}$ & $\begin{array}{l}\text { Theophylline } \\
\text { Potential for induction of }\end{array}$ \\
tachyarrhythmias & $\begin{array}{l}\text { History of recurrent palpitation } \\
\text { (suggesting possibility of latent pre- } \\
\text { excitation or dual AV node } \\
\text { physiology }\end{array}$ \\
&
\end{tabular}




\section{CONCLUSION}

Adenosine is widely used in hospital and, outside the UK, increasingly in the community; it is generally considered to be a safe and effective diagnostic and therapeutic agent. Clinicians know that it can cause bronchospasm, chest pain, and bradycardia, but may not be so aware of the potential for adenosine to induce asystole or tachyarrhythmias, particularly if there is previous evidence of sinus node dysfunction or paroxysmal tachycardia. As these arrhythmias may be life threatening, the administration of adenosine should only be carried out where there is rapid access to defibrillation and other antiarrhythmic agents. When a full history has been taken, medication recorded, and careful analysis of ECGs made, adenosine remains the agent of first choice for many tachyarrhythmias. Its potential to produce cardiovascular collapse on rare occasions must however be borne in mind.

Funding: none.

Conflicts of interest: none declared.

\section{REFERENCES}

1 Rankin AC, Oldroyd KG, Chong $\mathrm{E}$, et al. Value and limitations of adenosine in the diagnosis and treatment of narrow and broad complex tachycardias. $\mathrm{Br}$ Heart J 1989;62:195-203.

2 Tomcsanyi J, Tenczer J, Horvath L. Unusual effect of adenosine. Int J Cardiol 1995;49:89-91.

3 Brodsky MA, Hwang C, Hunter D, et al. Life-threatening alterations in heart rate after the use of adenosine in atrial flutter. Am Heart $J 1995$ 130.564-71.

4 McCollam PL, Uber WE, VanBakel AB. Adenosine-related ventricular asystole. Ann Intern Med 1993;18:315-16.

5 Camaiti A, Pieralli F, Olivotto I, et al. Prospective evaluation of adenosineinduced proarrhythmia in the emergency room. Eur J Emerg Med 2001:8:99-105.

6 Christopher M, Key CB, Persse DE. Refractory asystole and death following the prehospital administration of adenosine. Prehosp Emerg Care 2000;4:196-8.

7 Reed R, Falk JL, O'Brien J. Untoward reaction to adenosine therapy for supraventricular tachycardia. Am J Emerg Med 1991;9:566-70.

8 Webster DP, Daar AA. Prolonged bradyasystole and seizures following intravenous adenosine for supraventricular tachycardia. Am J Emerg Med 1993; 11:192-4

9 Pennell DJ, Mahmood S, Ell PJ, et al. Bradycardia progressing to cardiac arrest during adenosine thallium myocardial perfusion imaging in occult sinoatrial disease. Eur J Nucl Med 1994;21:170-2.

10 Dunn JS, Brost BC. Fetal bradycardia after IV adenosine for maternal PSVT. Am J Emerg Med 2000;18:234-5.

11 Pelleg A, Pennock RS, Kutalek SP. Proarrhythmic effects of adenosine: one decade of clinical data. Am J Ther 2002:9:141-7.

12 Tan HL, Spekhorst HH, Peters RJ, et al. Adenosine induced ventricular arrhythmias in the emergency room. Pacing Clin Electrophysiol 2001;24:450-5.

13 Misra D, Van Tosh A, Schweitzer P. Adenosine induced monomorphic ventricular tachycardia. Pacing Clin Electrophysiol 2000;23:1044-6.

14 Hingorani AD, Foley T. Non-sustained broad-complex tachycardia following intravenous adenosine. J Accid Emerg Med 1995;12:28-9.

15 Romer M, Candinas R. Adenosine-induced non-sustained polymorphic ventricular tachycardia. Eur Heart J 1994;15:281-2.

16 Smith JR, Goldberger JJ, Kadish AH. Adenosine induced polymorphic ventricular tachycardia in adults without structural heart disease. Pacing Clin Electrophysiol 1997;20:743-5.

17 Celiker A, Tokel K, Cil E, et al. Adenosine induced torsades de pointes in a child with congenital long QT syndrome. Pacing Clin Electrophysio 1994;17:1814-17.

18 Wesley RC, Turnquest P. Torsades de pointe after intravenous adenosine in the presence of prolonged QT syndrome. Am Heart J 1992;123:794-6.

19 Harrington GR, Froelich EG. Adenosine-induced torsades de pointes. Chest 1993;103:1299-301.

20 Kaplan IV, Kaplan AV, Fisher JD. Adenosine induced atrial fibrillation precipitating polymorphic ventricular tachycardia. Pacing Clin Electrophysiol 2000;23:140-1.

21 Ben-Sorek ES, Wiesel J. Ventricular fibrillation following adenosine administration. Arch Intern Med 1993;153:2701-2.

22 Pella J, Stancak B, Komanova E, et al. [Ventricular fibrillation after administration of adenosine]. [In Slovak]. Vnitr Lek 1995;41:832-5.

23 Parham WA, Mehdirad AA, Biermann KM, et al. Case report: adenosine induced ventricular fibrillation in a patient with stable ventricular tachycardia. J Interv Card Electrophysiol 2001;5:71-4.

24 Mulla N, Karpawich PP. Ventricular fibrillation following adenosine therapy for supraventricular tachycardia in a neonate with concealed Wolff-
Parkinson-White syndrome treated with digoxin. Pediatr Emerg Care 1995; 11:238-9.

25 Exner DV, Muzyka T, Gillis AM. Proarrhythmia in patients with the WolffParkinson-White syndrome after standard doses of intravenous adenosine. Ann Intern Med 1995; 122:351-2.

26 Shah CP, Gupta AK, Thakur RK, et al. Adenosine-induced ventricular fibrillation. Indian Heart J 2001;53:208-10.

27 Hernandez J, Ribeiro JA. Excitatory actions of adenosine on ventricular automaticity. Trends Pharmacol Sci 1996;17:141-4.

28 Slade AK, Garratt CJ. Proarrhythmic effect of adenosine in a patient with atrial flutter. Br Heart J 1993;70:91-2.

29 Falces Salvador C, Brugada Terradellas J, Barreto Filho JR, et al. [Transient atrioventricular conduction 1:1 in a patient with common atrial flutter following the administration of adenosine triphosphate]. [In Spanish]. Rev Esp Cardiol 1996;49:767-9.

30 Rankin AC, Rae AP, Houston A. Acceleration of ventricular response to atrial flutter after intravenous adenosine. Br Heart J 1993;69:263-3.

31 De Tsai W Tsai JH. Adenosine-induced ventricular flutter in an ethanolintoxicated patient. Am J Emerg Med 2002;20:135-6.

32 White RD. Acceleration of the ventricular response in paroxysmal lone atrial fibrillation following the injection of adenosine. Am J Emerg Med 1993;11:245-6.

33 Garratt CJ, O'Nunain S, Griffith MJ, et al. Effects of intravenous adenosine in patients with preexcited junctional tachycardias: therapeutic efficacy and incidence of proarrhythmic events. Am J Cardiol 1994;74:401-4.

34 Jaeggi E, Chiu C, Hamilton R, et al. Adenosine-induced atrial pro-arrhythmia in children. Can J Cardiol 1999:15:169-72.

35 Belhassen B, Pelleg A, Shoshani D, et al. Atrial fibrillation induced by adenosine triphosphate. Am J Cardiol 1984;53:1405-6.

36 Strickberger SA, Man KC, Daoud EG, et al. Adenosine-induced atrial arrhythmia: a prospective analysis. Ann Intern Med 1997;127:417-22.

37 Silverman AJ, Machado C, Baga JJ, et al. Adenosine-induced atrial fibrillation. Am J Emerg Med 1996; 14:300-1.

38 Garratt CJ, Antoniou A, Griffith MJ, et al. Use of intravenous adenosine in sinus rhythm as a diagnostic test for latent preexcitation. Am J Cardiol 1990:65:868-73.

39 Tebbenjohanns J, Pfeiffer D, Schumacher B, et al. Intravenous adenosine during atrioventricular re-entrant tachycardia; induction of atrial fibrillation with rapid conduction over an accessory pathway. Pacing Clin Electrophysiol 1995; 18:743-6.

40 Cowell RP, Paul VE, Ilsley CD. Haemodynamic deterioration after treatment with adenosine. Br Heart J 1994;71:569-71.

41 Curtis AB, Belardinelli L, Woodard DA, et al. Induction of atrioventricular node reentrant tachycardia with adenosine: differential effect of adenosine on fast and slow atrioventricular node pathways. J Am Coll Cardiol 1997:30:1778-84

42 Lai WT, Lee KT, Wu JC, et al. Differential effects of adenosine on antegrade fast pathway, antegrade slow pathway, and retrograde fast pathway in atrioventricular nodal reentry. Cardiology 2002;97:147-54.

43 Dougherty AH, Gilman JK, Wiggins S, et al. Provocation of atrioventricular reentry tachycardia: a paradoxical effect of adenosine. Pacing Clin Electrophysiol 1993; 16:8-12

44 Vora A, Lokhandwala Y. Adenosine-induced tachycardia: what is the mechanism? J Cardiovasc Electrophysiol 2000;11:491-2.

45 Orebaugh SL, Handy M. Intravenous adenosine therapy accelerating rate of paroxysmal supraventricular tachycardia. Am J Emerg Med 1992; 10:326-30

46 Watt AH, Routledge PA. Transient bradycardia and subsequent sinus tachycardia produced by intravenous adenosine in healthy adult subjects. Br J Clin Pharmacol 1986;21:533-6.

47 Till J, Shinebourne EA, Rigby ML, et al. Efficacy and safety of adenosine in the reatment of supraventricular tachycardia in infants and children. $\mathrm{Br}$ Heart 1989:62:204-11

48 Garratt CJ, Griffith MJ, O'Nunain S, et al. Effects of intravenous adenosine on antegrade refractoriness of accessory atrioventricular connections. Circulation $1991 ; 84: 1962-8$

49 Burnett D, Abi-Samra F, Vacek JL. Use of intravenous adenosine as a noninvasive diagnostic test for sick sinus syndrome. Am Heart J 1999;137:435-8.

50 Hinschen AK, Rose'Meyer RB, Headrick JP. Age-related changes in A(1)adenosine receptor-mediated bradycardia. Am J Physiol Heart Circ Physio 2000;278:H789-95.

51 Chang M, Wrenn K. Adenosine dose should be less when administered through a central line. J Emerg Med 2002;22:195-8.

52 Roelke M, Yurchak PM. Adenosine and supraventricular tachycardia. N Engl J Med 1992;326:1221-2

53 Giagounidis AA, Schafer S, Klein RM, et al. Adenosine is worth trying in patients with paroxysmal supraventricular tachycardia on chronic theophylline medication. Eur J Med Res 1998;3:380-2

54 Tebbenjohanns J, Niehaus M, Korte T, et al. Noninvasive diagnosis in patients with undocumented tachycardias: value of the adenosine test to predict AV nodal reentrant tachycardia. J Cardiovasc Electrophysiol 1999;10:916-23.

55 Belhassen B, Fish R, Viskin S, et al. Adenosine-5'-triphosphate test for the noninvasive diagnosis of concealed accessory pathway. J Am Coll Cardiol 2000;36:803-10. 